\title{
Different Patterns of Left Ventricular Hypertrophy in Metabolically Healthy and Insulin-Resistant Obese Subjects
}

\author{
Angela Sciacqua ${ }^{1, *,+}$, Antonio Cimellaro ${ }^{2, \dagger}{ }^{\dagger}$, Luana Mancuso ${ }^{1}$, Sofia Miceli ${ }^{1}$, Velia Cassano ${ }^{1}$, \\ Maria Perticone ${ }^{3}{ }^{\circledR}$, Teresa V. Fiorentino ${ }^{1}$, Francesco Andreozzi ${ }^{1}{ }^{\circledR}$, Elena Succurro ${ }^{1}$, \\ Giorgio Sesti ${ }^{4}(\mathbb{D})$ and Francesco Perticone ${ }^{1}(\mathbb{D})$ \\ 1 Department of Medical and Surgical Sciences, University Magna Græcia of Catanzaro, \\ 88100 Catanzaro, Italy; luana.mancuso@hotmail.it (L.M.); sofy.miceli@libero.it (S.M.); \\ velia.cassano@libero.it (V.C.); vanessa.fiorentino@unicz.it (T.V.F.); andreozzif@unicz.it (F.A.); \\ succurro@unicz.it (E.S.); perticone@unicz.it (F.P.) \\ 2 Internal Medicine Unit, Pugliese-Ciaccio Hospital, 88100 Catanzaro, Italy; antocime@hotmail.it \\ 3 Department of Experimental and Clinical Medicine, University Magna Græcia of Catanzaro, \\ 88100 Catanzaro, Italy; mariaperticone@hotmail.com \\ 4 Department of Clinical and Molecular Medicine, University of Rome-Sapienza, 00161 Rome, Italy; \\ giorgio.sesti@uniroma1.it \\ * Correspondence: sciacqua@unicz.it; Tel.: +39-0961-3647013; Fax: +39-0961-3647634 \\ + These authors equally contributed to the work.
}

Received: 25 November 2019; Accepted: 3 February 2020; Published: 5 February 2020

check for updates

\begin{abstract}
Obese subjects showed different cardiovascular risk depending by different insulin sensitivity status. We investigated the difference in left ventricular mass and geometry between metabolically healthy (MHO) and unhealthy (MUHO) obese subjects. From a cohort of 876 obese subjects ( $48.3 \pm 14.1$ years) without cardio-metabolic disease and stratified according to increasing values of Matsuda index after $75 \mathrm{~g}$ oral glucose tolerance test, we defined MHO $(n=292)$ those in the upper tertile and MUHO $(n=292)$ those in the lower tertile. All participants underwent echocardiographic measurements. Left ventricular mass was calculated by Devereux equation and normalized by height ${ }^{2,7}$ and left ventricular hypertrophy (LVH) was defined by values $>44 \mathrm{~g} / \mathrm{m}^{2.7}$ for females and $>48 \mathrm{~g} / \mathrm{m}^{2.7}$ for males. Left ventricular geometric pattern was defined as concentric or eccentric if relative wall thickness was higher or lower than 0.42 , respectively. MHO developed more commonly a concentric remodeling $(19.9$ vs. $9.9 \% ; p=0.001)$ and had a reduced risk for LVH (OR 0.46; $p<0.0001$ ) than MUHO, in which the eccentric type was more prevalent (40.4 vs. $5.1 \%$; $p<0.0001$ ). We demonstrated that obese subjects—-matched for age, gender and BMI-have different left ventricular mass and geometry due to different insulin sensitivity status, suggesting that diverse metabolic phenotypes lead to alternative myocardial adaptation.
\end{abstract}

Keywords: obesity; metabolically healthy obesity; insulin-resistance; left ventricular hypertrophy; cardiac remodeling

\section{Introduction}

Obesity represents a crucial problem for public health due to reach epidemic proportion worldwide and to strongly associate with an increased risk for type 2 diabetes mellitus and cardiovascular (CV) disease, both conditions able to worse clinical outcome [1]. However, there is increasing evidence that sub-phenotypes of obesity exist, thus questioning the apparent linear relationship between increased body mass index (BMI) and cardio-metabolic risk [2-4]. In fact, approximately from $10 \%$ to $25 \%$ of 
obese subjects are free of any metabolic abnormalities, are relatively insulin sensitive and have a rather favorable CV risk profile, thus they exhibit metabolically healthy obesity (MHO) [3-5]. This wide range may be justified by the fact that, despite the enhanced interest in $\mathrm{MHO}$, there are not unique criteria to define $\mathrm{MHO}$, thus the implications of $\mathrm{MHO}$ phenotype on $\mathrm{CV}$ risk is still not clear.

It is known that left ventricular hypertrophy (LVH) represents an independent risk factor for CV morbidity and mortality in different clinical settings [6,7]. However, the increase of left ventricular mass (LVM) is not only a consequence of adaptive cardiac remodeling to hemodynamic overload, but it recognizes a complex and multifactorial pathogenesis. In particular, relevant studies have demonstrated that metabolic factors have an important role in the cardiac remodeling and LVM increase [8-14]. Several evidences have demonstrated that obesity is an independent risk factor for LVH $[15,16]$. In fact, independently of arterial hypertension, increased adiposity may promote structural and functional changes in the myocardium through hemodynamic and non-hemodynamic factors [17]. According with this, LVH and left ventricular diastolic dysfunction are present in young obese before sustained hypertension development [18]. In consideration of the different obesity phenotypes, it is possible to speculate that it is not obesity itself, but the obesity-related metabolic abnormalities that affect LVM and LVH development with possible consequence on clinical outcome.

Currently, there are few data about the association between MHO and LVH and this issue remains to be elucidated. Thus, the aim of the present study is to evaluate whether various obesity phenotypes may affect, in a different way, left ventricular remodeling.

\section{Materials and Methods}

\subsection{Study Population}

From the CATAnzaro MEtabolic RIsk factors Study (CATAMERIS), a prevention campaign for cardio-metabolic risk factors performed at University "Magna Graecia" of Catanzaro [19], an initial cohort of 876 Caucasian obese subjects was considered. All participants, aged $48.3 \pm 14.1$ years (380 males, 496 females), showed a BMI $\geq 30 \mathrm{~kg} / \mathrm{m}^{2}$, without history of CV and metabolic disease, and after a 12-h overnight fast underwent a $75 \mathrm{~g}$ oral glucose tolerance test (OGTT) with 0, 30-, 60-, 90- and 120-min sampling for plasma insulin and glucose. Then, the cohort was stratified into tertiles according to increasing values of Matsuda index, a previously validated insulin sensitivity parameter derived from OGTT [20]. Subjects in the upper tertile-defined as MHO $(n=292)$-and those in the lower tertile—defined as metabolically unhealthy obese (MUHO) $(n=292)$-were included in the study. All diabetic patients were excluded from the study. Moreover, subjects under 18 and over 65 years, pregnant or nursing, with history or clinical evidence of alcohol/drug abuse, diabetes, hypertension, coronary or peripheral artery disease, valvular heart disease, malignant disease, coagulation abnormalities, chronic gastrointestinal disease with malabsorption, chronic pancreatitis, endocrine disorders, liver or renal failure-defined as estimated glomerular filtration rate (eGFR) $<60 \mathrm{~mL} / \mathrm{min} / 1.73 \mathrm{~m}^{2}$, on any pharmacological treatment able to affect glucose metabolism, were also excluded. All the participants underwent anamnesis, physical examination with determination of waist circumference, weight, height and BMI expressed as $\mathrm{kg} / \mathrm{m}^{2}$, heart rate and measurements of systolic and diastolic blood pressure as indicated by current guidelines [21]. All the evaluations were made according to Declaration of Helsinki, after obtaining approval by local Ethical Committee and written informed consent by each subject.

\subsection{Laboratory Determinations}

Blood samples after 12-h overnight fast were obtained from all participants. Glucose, triglyceride, low (LDL) and high (HDL) density lipoprotein cholesterol concentrations were determined by enzymatic methods (Roche, Basel, Switzerland). Plasma insulin concentration was obtained with a chemiluminescence-based assay (Immulite, Siemens, Italy) and high-sensitivity C-reactive protein (hs-CRP) was measured by automated instrument (CardioPhase_hs-CRP, Siemens, Milano, Italy). 
Serum creatinine and uric acid (UA) were measured in the routine laboratory by an automated technique based on the measurement of Jaffe chromogen and by the URICASE/POD (Boehringer Mannheim, Mannheim, Germany) method implemented in an autoanalyzer. Values of eGFR were calculated by using the CKD-EPI equation [22].

\subsection{Insulin-Resistance and Sensitivity}

To measure insulin-resistance, the homeostasis model assessment of insulin-resistance (HOMA-IR) index was calculated as follow:

$$
\text { (fasting insulin }(\mu \mathrm{U} / \mathrm{mL}) \times \text { fasting glucose }(\mathrm{mmol} / \mathrm{L})) / 22.5
$$

Conversely, insulin sensitivity was evaluated by Matsuda index as follow:

$10,000 /$ square root of (fasting glucose $(\mathrm{mmol} / \mathrm{L}) \times$ fasting insulin $(\mathrm{mU} / \mathrm{L}))$ $\times($ mean glucose $\times$ mean insulin during OGTT)

The Matsuda index was previously used to distinguish different metabolic obesity phenotypes [4,5], due to its strong relation to euglycemic-hyperinsulinemic clamp, which represents the gold standard test for measuring insulin sensitivity [20].

\subsection{Echocardiographic Measurements}

Tracings were taken with patients in a partial left decubitus position using a VIVID-7 Pro ultrasound machine (GE Technologies, Milwaukee, WI, USA) with an annular phased array 2.5-MHz transducer. Only frames with optimal visualization of cardiac structures were considered for readings. The mean values from at least five measurements of each parameter for each patient were computed. All the readings were performed by the same experienced investigator to optimize the reproducibility. In our laboratory, the CVs were $3.85 \%$ for posterior wall thickness, $3.70 \%$ for interventricular septum thickness, $1.50 \%$ for left ventricular internal diameter, and 5.10\% for LVM. The echocardiographer was blinded to MHO/MUHO status of the subjects.

Tracings were recorded under two-dimensional guidance, and M-mode measurements were taken at the tip of the mitral valve or just below, as suggested by current guidelines [23]. The measurement of left atrial (LA) volume was performed using the area-length (L) method. We measured single-plane area of the LA from the four-chamber view, at end-ventricular systole, guaranteeing that there was no foreshortening of the LA. LA volume index (LAVI) was obtained indexing LA volume by body surface area (BSA). Left ventricular (LV) diastolic function was evaluated measuring the peak trans-valvular flow velocity in early diastole (E wave), the peak trans-valvular flow velocity in late diastole (A wave) and E-to-A ratio. Measurements of interventricular septum thickness, posterior wall thickness, and LV internal diameter (LVID) were made at end-diastole and end systole. LV end-diastolic (LVEDV) and end-systolic volume (LVESV) were measured according to Simpson method and indexed for BSA. LVM was calculated using the Devereux equation [24] and normalized by height ${ }^{2,7}$ [LVM index (LVMI)] according to de Simone and co-workers [25]. LV hypertrophy (LVH) was defined by a value of LVMI $>44 \mathrm{~g} / \mathrm{m}^{2.7}$ for females and $>48 \mathrm{~g} / \mathrm{m}^{2.7}$ for males [23]. Finally, to define the different left ventricular geometric patterns, the relative wall thickness (RWT) was calculated according to the following formula:

$$
(2 \times \text { posterior wall thickness)/(LVID at end-diastole) }
$$

RWT allows categorization of an increase in LVM as either concentric (RWT > 0.42) or eccentric (RWT $\leq 0.42$ ) hypertrophy and allows the identification of concentric remodeling (normal LVM with increased RWT) [23]. 


\subsection{Statistical Analysis}

To test the differences between MHO and MUHO groups unpaired Student' $t$-test for clinical and biological data was performed and $\chi^{2}$ test was considered for categorical variables. Univariate logistic regression analysis was performed to test the effect of different covariates on LVH. MHO phenotype was considered as dichotomous variable so as gender; the other covariates were age, BMI, pulse pressure, LDL-cholesterol, uric acid, eGFR and hs-CRP. Afterwards, only variables achieving statistical significance at univariate model were included in a stepwise logistic regression model to define the independent predictors of LVH. Data are reported as mean \pm standard error of the mean (SEM) and differences were considered significant at $p<0.05$. All comparisons were performed using the statistical package SPSS 20.0 for Windows (SPSS Inc., Chicago, IL, USA).

\section{Results}

\subsection{Study Population}

Anthropometric, hemodynamic and biochemical characteristics of the whole study population and according to the different obesity phenotypes are reported in Table 1. No differences in gender distribution, age, BMI, smokers, diastolic blood pressure (DBP) and LDL-cholesterol values were observed between MUHO and MHO groups. Of interest, MUHO showed a worse hemodynamic, metabolic and inflammatory profile when compared to $\mathrm{MHO}$, as suggested by significantly higher values of systolic blood pressure (SBP) and pulse pressure, heart rate, waist circumference, triglycerides, fasting glucose, fasting insulin, HOMA-IR, hs-CRP and uric acid. Conversely, MHO had lower levels of Matsuda index, HDL-cholesterol and eGFR when compared to MUHO.

Table 1. Anthropometric, hemodynamic and biochemical characteristics of the whole study population and according to different obesity phenotypes.

\begin{tabular}{ccccc}
\hline & All $(n=876)$ & MHO $(n=292)$ & MUHO $(n=292)$ & $p$ \\
\hline Gender m/f & $380 / 496$ & $127 / 165$ & $132 / 160$ & $0.677^{*}$ \\
Age, years & $48.3 \pm 0.5$ & $47.4 \pm 0.8$ & $48.3 \pm 0.9$ & 0.454 \\
Smokers, $n(\%)$ & $171(19.5)$ & $61(20.9)$ & $57(19.5)$ & $0.680^{*}$ \\
BMI, $\mathrm{kg} / \mathrm{m}^{2}$ & $36.0 \pm 0.2$ & $35.0 \pm 0.4$ & $35.9 \pm 0.3$ & 0.080 \\
WC, cm & $109.6 \pm 0.4$ & $106.7 \pm 0.6$ & $113.4 \pm 0.9$ & $<0.0001$ \\
SBP, mmHg & $132.7 \pm 0.5$ & $130.5 \pm 0.7$ & $134.3 \pm 1.1$ & 0.005 \\
DBP, mmHg & $85.1 \pm 0.3$ & $84.9 \pm 0.5$ & $85.5 \pm 0.6$ & 0.478 \\
Pulse Pressure, mmHg & $47.6 \pm 0.5$ & $45.6 \pm 0.7$ & $48.9 \pm 1.1$ & 0.012 \\
Heart rate, bpm & $72.8 \pm 0.4$ & $69.8 \pm 0.6$ & $75.7 \pm 0.7$ & $<0.0001$ \\
LDL-cholesterol, mg/dL & $124.6 \pm 1.2$ & $124.4 \pm 2.1$ & $124.8 \pm 2.3$ & 0.913 \\
HDL-cholesterol, mg/dL & $49.2 \pm 0.4$ & $51.1 \pm 0.7$ & $45.5 \pm 0.7$ & $<0.0001$ \\
Triglycerides, mg/dL & $128.9 \pm 2.2$ & $116.6 \pm 3.4$ & $149.5 \pm 4.6$ & $<0.0001$ \\
Serum creatinine, mg/dL & $0.8 \pm 0.01$ & $0.7 \pm 0.01$ & $0.8 \pm 0.01$ & 0.002 \\
eGFR, mL/min/1.73 m ${ }^{2}$ & $108.5 \pm 0.9$ & $118.8 \pm 1.9$ & $96.5 \pm 1.1$ & $<0.0001$ \\
Uric acid, mg/dl & $5.2 \pm 0.05$ & $4.9 \pm 0.08$ & $5.6 \pm 0.09$ & $<0.0001$ \\
Fasting glucose, mg/dl & $94.6 \pm 0.5$ & $90.9 \pm 0.6$ & $99.6 \pm 0.9$ & $<0.0001$ \\
Fasting insulin, $\mu \mathrm{dU} / \mathrm{ml}$ & $11.6 \pm 0.2$ & $9.1 \pm 0.2$ & $15.6 \pm 0.3$ & $<0.0001$ \\
Matsuda index & $62.6 \pm 0.9$ & $91.4 \pm 1.9$ & $39.1 \pm 0.5$ & $<0.0001$ \\
HOMA-IR & $3.6 \pm 0.1$ & $2.1 \pm 0.1$ & $6.4 \pm 0.2$ & $<0.0001$ \\
hs-CRP, mg/L & $3.5 \pm 0.1$ & $3.0 \pm 0.1$ & $3.9 \pm 0.2$ & $<0.0001$ \\
\hline
\end{tabular}

* by $\chi^{2}$ test. $\mathrm{MHO}=$ metabolically healthy obese; $\mathrm{MUHO}=$ metabolically unhealthy obese; $\mathrm{BMI}=$ body mass index $\mathrm{WC}=$ waist circumference; $\mathrm{SBP}=$ systolic blood pressure; $\mathrm{DBP}=$ diastolic blood pressure; $\mathrm{LDL}=$ low-density lipoprotein; HDL = high-density lipoprotein; eGFR = estimated glomerular filtration rate; HOMA-IR = homeostatic model assessment of insulin resistance; hs-CRP = high-sensitivity C-reactive protein. 


\subsection{Echocardiographic Measurements}

Echocardiographic parameters of the whole study population and according to the different obesity phenotypes can be observed in Table 2. MUHO group showed significantly higher values of LAVI and left ventricular cavity size, expressed by left ventricular end-diastolic diameter (LVEDD) and LVEDV indexed for BSA (LVEDVI) (Figure 1), when compared to MHO group. Moreover, MUHO subjects had increased diastolic interventricular septum (dIVS) and reduced diastolic posterior wall (dPW), with higher values of LVMI (Figure 1). In addition, MUHO had a worse diastolic function expressed by a significantly reduced E/A ratio and a lower RWT in comparison with MHO subjects.

Table 2. Echocardiographic parameters of the whole study population and according to different obesity phenotypes.

\begin{tabular}{ccccc}
\hline & All $(\boldsymbol{n}=\mathbf{8 7 6})$ & MHO $(\boldsymbol{n = 2 9 2 )}$ & MUHO $(\boldsymbol{n = 2 9 2})$ & $p$ \\
\hline LAVI, $\mathrm{mL} / \mathrm{m}^{2}$ & $29.7 \pm 0.4$ & $26.9 \pm 0.4$ & $32.1 \pm 0.7$ & $<0.0001$ \\
LVEDD, cm & $4.92 \pm 0.01$ & $4.83 \pm 0.02$ & $5.01 \pm 0.02$ & $<0.0001$ \\
LVEDVI, $\mathrm{mL} / \mathrm{m}^{2}$ & $61.7 \pm 0.5$ & $58.5 \pm 0.7$ & $63.9 \pm 0.9$ & $<0.0001$ \\
dPW, cm & $1.01 \pm 0.01$ & $1.03 \pm 0.01$ & $0.99 \pm 0.01$ & 0.029 \\
dIVS, cm & $1.12 \pm 0.01$ & $1.10 \pm 0.01$ & $1.15 \pm 0.01$ & $<0.0001$ \\
LVMI, g/m 2.7 & $52.5 \pm 0.6$ & $49.3 \pm 1.1$ & $54.9 \pm 1.2$ & $<0.0001$ \\
E/A & $0.96 \pm 0.01$ & $1.04 \pm 0.02$ & $0.87 \pm 0.02$ & $<0.0001$ \\
RWT & $0.41 \pm 0.01$ & $0.43 \pm 0.01$ & $0.40 \pm 0.01$ & $<0.0001$ \\
\hline
\end{tabular}

$\mathrm{MHO}=$ metabolically healthy obese; $\mathrm{MUHO}=$ metabolically unhealthy obese; LAVI = left atrial volume index; LVEDD = left ventricular end-diastolic diameter; LVEDVI = left ventricular end-diastolic volume index; dPW = diastolic posterior wall; $\mathrm{dIVS}=$ diastolic interventricular septum; LVMI = left ventricular mass index; RWT= relative wall thickness.
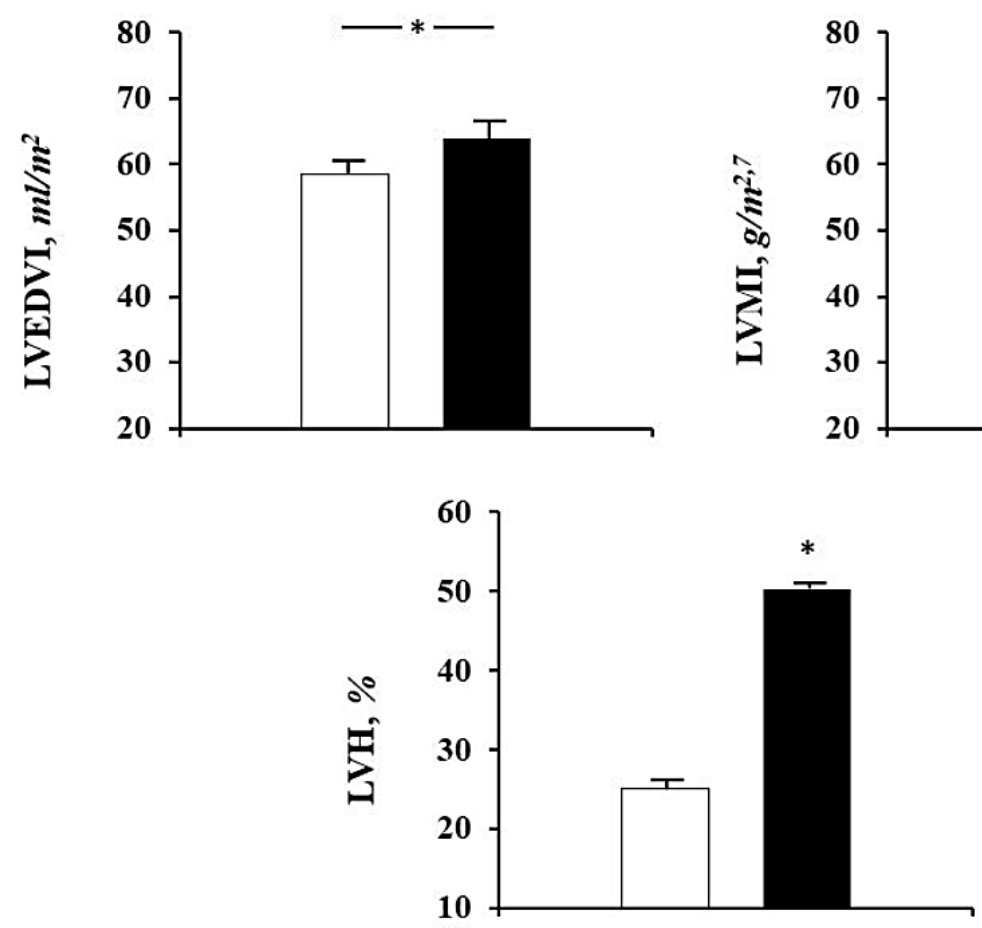
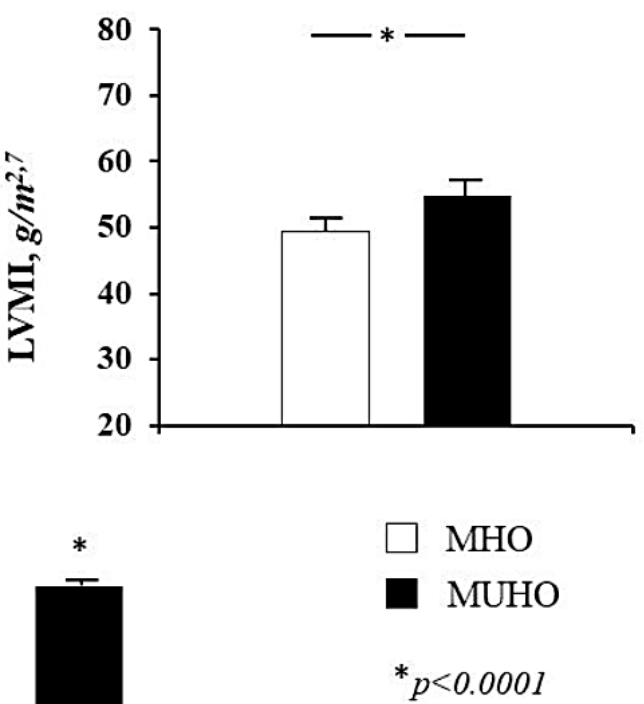

Figure 1. Mean values of left ventricular end-diastolic volume indexed for body surface area (LVEDVI), left ventricular mass index (LVMI) and percentage of patients with left ventricular hypertrophy $(\mathrm{LVH})$ according to obesity phenotype. $\mathrm{MHO}=$ metabolically healthy obese; $\mathrm{MUHO}=$ metabolically unhealthy obese.

Patterns of left ventricular geometry of the whole study population and according to the two obesity phenotypes are showed in Table 3. The prevalence of LVH was significantly higher in MUHO 
than $\mathrm{MHO}$ (50.3\% vs. $25.0 \%, p<0.0001$ ) (Figure 1). Among those without LVH, concentric remodeling was more common in MHO group (44.9\% vs. 30.2\%, $p<0.0001)$. With regards to hypertrophy pattern, the eccentric type was prevailing in MUHO group while the concentric type was more prevalent among MHO subjects (Figure 2), suggesting a different ventricular adaptation in relation to obesity phenotype.

Table 3. Patterns of left ventricular geometry in the whole study population and according to different obesity phenotypes.

\begin{tabular}{lcccc}
\hline & All $(\boldsymbol{n}=\mathbf{8 7 6})$ & MHO $(\boldsymbol{n = 2 9 2 )}$ & MUHO $(\boldsymbol{n = 2 9 2 )}$ & $p$ \\
\hline LVH-, $n(\%)$ & $539(61.5)$ & $219(75.0)$ & $145(49.7)$ & $<0.0001$ \\
Normal, $n(\%)$ & $212(24.2)$ & $88(30.1)$ & $57(19.5)$ & 0.003 \\
Concentric remodeling, $n(\%)$ & $327(37.3)$ & $131(44.9)$ & $88(30.2)$ & $<0.0001$ \\
\hline LVH+, $n(\%)$ & $337(38.5)$ & $73(25.0)$ & $147(50.3)$ & $<0.0001$ \\
Eccentric remodeling, $n(\%)$ & $206(23.5)$ & $15(5.1)$ & $118(40.4)$ & $<0.0001$ \\
Concentric remodeling, $n(\%)$ & $131(15.0)$ & $58(19.9)$ & $29(9.9)$ & 0.001 \\
\hline
\end{tabular}

$\mathrm{MHO}=$ metabolically healthy obese; $\mathrm{MUHO}=$ metabolically unhealthy obese; $\mathrm{LVH}=$ left ventricular hypertrophy.

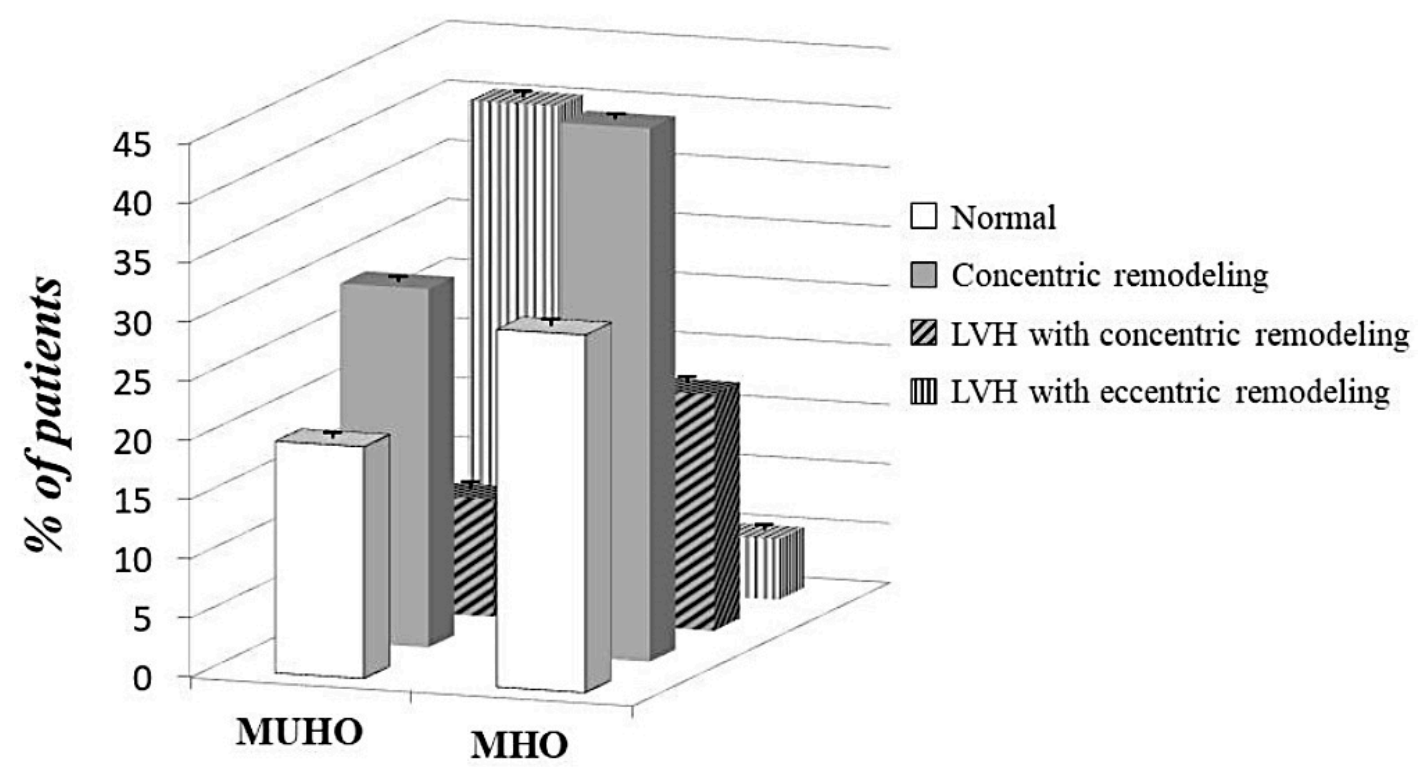

Figure 2. Different patterns of left ventricular geometry according to obesity phenotypes. MHO = metabolically healthy obese; $\mathrm{MUHO}=$ metabolically unhealthy obese; $\mathrm{LVH}=$ left ventricular hypertrophy. Differences between groups: $p=0.003$ for normal pattern; $p=0.001$ for LVH with concentric pattern; $p<0.0001$ for other patterns.

\subsection{Logistic Regression Analysis on LVH Risk}

A logistic regression analysis was performed to test the effect of different variables, including $\mathrm{MHO}$, on the risk of LVH (Table 4). At univariate model, both gender and age were associated to higher risk of $\mathrm{LVH}$, respectively doubled for males and increased of $25 \%$ for every 10 years of aging. Conversely, MHO phenotype and eGFR resulted to be protective factors on LVH development; in particular, probability of LVH decreases by $57 \%$ in MHO subjects and $9 \%$ for every $10 \mathrm{~mL} / \mathrm{min} / \mathrm{m}^{2}$ of increase in eGFR. These results were mostly confirmed at multivariate model, with protective effect of $\mathrm{MHO}(\mathrm{OR} 0.46 ; p<0.0001)$ and eGFR (OR 0.91; $p=0.009)$, and increased risk for age (OR 1.22; $p=0.001)$ and male gender (OR 2.64; $p<0.0001)$. 
Table 4. Univariate and multivariate stepwise logistic regression analysis with left ventricular hypertrophy as dependent variable, in whole study population.

\begin{tabular}{ccccc}
\hline & \multicolumn{2}{c}{ Univariate } & \multicolumn{2}{c}{ Multivariate } \\
\cline { 2 - 5 } & Odds Ratio & $p$ & Odds Ratio & $p$ \\
\hline MHO phenotype, yes/no & 0.43 & $<0.0001$ & 0.46 & $<0.0001$ \\
eGFR, 10 mL/min/1.73 m ${ }^{2}$ & 0.91 & 0.008 & 0.91 & 0.009 \\
Age, 10 years & 1.25 & $<0.0001$ & 1.25 & $<0.0001$ \\
Gender, male & 2.62 & $<0.0001$ & 2.64 & $<0.0001$ \\
BMI, kg/m 2 & 1.02 & 0.131 & & \\
Pulse pressure, 10 mmHg & 1.03 & 0.631 & & \\
LDL-cholesterol, 10 mg/dL & 0.99 & 0.844 & & \\
Uric acid, mg/dL & 0.96 & 0.556 & & \\
hs-CRP, mg/L & 0.95 & 0.159 & & \\
\hline
\end{tabular}

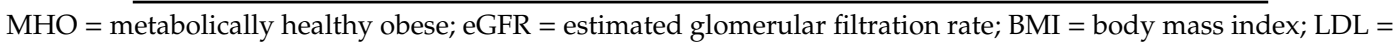
low-density lipoprotein; hs-CRP = high-sensitivity C-reactive protein.

\section{Discussion}

In this study, we have demonstrated a strong association between obesity and LVH in a large cohort of obese subjects without history of cardio-metabolic disease. The prevalence of LVH was 38.5\% in our study population. Most importantly, the association between obesity and increased cardiac mass was strongly affected by metabolic phenotype, but not by BMI. Indeed, our data showed that LVH was more prevalent in MUHO than MHO subjects (50.3\% vs. $25.0 \%$ ) and the risk for LVH decreased by $57 \%$ in $\mathrm{MHO}$ group. Another interesting finding is the different ventricular remodeling pattern among the groups: MHO group had a more prevalent concentric pattern in comparison with MUHO group, which instead showed a higher prevalence of eccentric geometry. Of interest, MUHO had also a worse diastolic function, expressed by lower E/A ratio, when compared to MHO.

On pathophysiological side, relationship between adipose tissue and cardiac damage appears extremely complex and our data contribute to clarify the underlying mechanisms. As expected, MUHO group had a less favorable cardio-metabolic profile due to higher insulin-resistance. In our study, MUHO subjects—compared to MHO matched for age, gender and BMI—had significantly higher values of waist circumference, triglycerides, SBP, pulse pressure and hs-CRP, as well as lower levels of HDL-cholesterol. Taken together, these anthropometric and biochemical data are expression of insulin-resistance as well as the most important features of metabolic syndrome [26,27]. It has been demonstrated that central obesity, clinically expressed as elevated waist circumference, is characterized by reduced insulin sensitivity that in turn leads to free fatty acid flux to the liver with increased release of lipoprotein rich in triglycerides [28]; moreover, abnormal activity of adipocyte in central obesity leads to enhanced subclinical inflammation that is strongly associated with insulin resistance $[29,30]$. Finally, accumulating evidence showed the strong association between insulin-resistance and the continuum of CV disease, from endothelial dysfunction [31-35] to vascular [36,37] and cardiac damage [38], further corroborating the importance of metabolic profile in different settings of patients.

In view of this we have demonstrated that, in obese individuals, LVH and its geometry do not necessarily change directly with the expansion of the adipose tissue but may be affected by different metabolic phenotype, with important implications on clinical outcome and therapeutic strategy. We can suppose that the prevalent eccentric pattern of LVH in MUHO individuals may be attributable to the predominance of the obesity-related volume overload that determines elongation of cardiomyocytes by sarcomeric addition in series as adaptive mechanism and, consequently, an eccentric $\mathrm{LVH}$. This volume overload is probably related to an excessive hydrosaline retention determined by insulin-resistance and reduced renal function, as evidenced by significantly lower levels of eGFR in MUHO group. Logistic regression analysis confirmed the role of renal function on left ventricular geometry: for each increase of $10 \mathrm{~mL} / \mathrm{min} / \mathrm{m}^{2}$ of eGFR, LVH risk decreased by $9 \%$. Regarding insulin-resistance, the associated hyperinsulinemia directly increases cardiac mass and left ventricle 
dysfunction, through the interaction between insulin, its receptor and insulin-like growth factor-1 (IGF-1) receptor, expressed in the myocardium [39]. Moreover, insulin-resistance reduces IGF-1 blood levels, for negative balance and spill-over effect between hormones. Reduced levels of IGF-1 are associated with higher circulating levels of growth hormone and insulin that promote hypertrophy and myocardial fibrosis [8,40]. Moreover, lower amounts of plasma IGF-1 could contribute to the reduced eGFR observed in MUHO individuals as compared with MHO ones. Previous studies have in fact reported that IGF-1 increases both renal blood flow and renal filtration by stimulating IGF-1 receptors [41,42]. IGF-1 is a potent vasodilator by stimulating nitric oxide biosynthesis through up-regulation of endothelial nitric oxide synthase expression in endothelial cells. According to these pathophysiological mechanisms, recent evidence showed that MUHO individuals have a 2.5 fold increased risk of impaired renal function compared to $\mathrm{MHO}$ subjects, and a 7.0 fold increased risk compared with non-obese subjects [5]. Insulin-resistance also determines the hyperactivation of other systems such as renin-angiotensin-aldosterone system (RAAS) and symphatetic nervous system, with consequent hemodynamic and no hemodynamic effects. Furthermore, our group has demonstrated that there is a strong association between increased RAAS attivation, circulating insulin levels and LVH [14]. This is promoted by the harmful effect of angiotensin II, which can increase the expression of profibrotic substances, such as plasminogen activator inhibitor type-1 and transforming growth factor- $\beta$, in addition to the direct profibrotic effect of aldosterone. To confirm this, the use of the angiotensin receptor blocker losartan in obese rats reduces the risk of myocardial fibrosis and LVH. This may be determined by the improvement of angiotensin II-related insulin-resistance, as evidenced by reduction of insulin levels and by improvement of glucose parameters [43]. Insulin-resistance induced by angiotensin II, in turn, promotes further activation of RAAS and symphatetic nervous system, feeding a vicious circle that promotes myocardial damage [33]. Moreover, such authors have documented that insulin-resistance induces the shift of cardiac metabolism towards free fatty acid oxidation, leading to lower myocardial energy efficiency, mitochondrial dysfunction, reactive oxygen species production and cardiomyocytes senescence, apoptosis and fibrotic substitution [44]. Finally, all these mechanisms can further favour a condition of mild chronic inflammation, that in MUHO may be facilitated by an increased visceral adipose tissue, with systemic and also paracrine secretion of inflammatory adipokines such as tumor necrosis factor alpha, monocyte chemoattractant protein-1 and interleukin-6, that may further increase cardiac damage and remodeling [45]. The present study showed that the interaction between all these systems is not the same among obese subjects, and depends by different metabolic phenotypes. Therefore, cardiac remodeling in the obese is very complex and involves different aspects. Obesity is an independent risk factor for LVH, but it is also associated with other risk factors, such as hypertension and sleep apnea, which can amplify the effect of obesity on cardiac remodeling, through a combination of volume and pressure overload. This may have consequences on LVH and its geometry pattern, influencing left ventricular cavity and parietal thicknesses [46].

The results of the present study have great biological plausibility because, although the structural remodeling of the myocardium represents an adaptive factor able to guarantee good functional performances in various systemic pathologies, including obesity, it is also true that LVH is recognized as an independent predictor of CV events. Among the organ damage indicators, LVH is an independent risk factor for mortality and morbidity and is the only indicator of organ damage whose regression is associated with improved prognosis. It is known that, in patients with LVH, the reduction of LVM is associated with favorable pathophysiological changes such as improvement of systolic function parameters and diastolic filling, increase of coronary reserve, reduction of ventricular arrhythmias and, probably, prevention of atrial fibrillation [47].

Our data support the hypothesis that the different metabolic phenotypes of obesity have a different effect on the left ventricular geometry, which is strongly influenced by the metabolic setting. This may have important therapeutic implications suggesting the usefulness, in MUHO patients, of drugs able to reduce the volume overload, such as diuretics, as well as sodium restriction. Furthermore, 
it is recommended to use, in obese patients, drugs that can modulate RAAS, such as ACE inhibitors or angiotensin receptor blockers, that are able to reduce blood pressure and cardiac remodeling. In addition, weight loss is fundamental. In fact, a recent case-control study [48] showed that the reduction of body weight determines a positive cardiac remodeling, as evidenced by the improvement of ventricular volumes, wall thickness and ventricular mass. We do not know the prognostic impact of different ventricular remodeling pattern observed in $\mathrm{MHO}$ individuals, compared with MUHO. Moreover, this pattern may evolve, because of a metabolic profile worsening, from a concentric remodeling towards a dilated type and heart failure. A better phenotypic characterization of obese subjects can be useful in order to evaluate their cardio-metabolic risk profile and to use more targeted therapeutic approaches.

\section{Conclusions}

Our study demonstrates that obese subjects - matched for age, gender and BMI-have different LVM and geometry due to different insulin sensitivity status. MHO develop more commonly a concentric remodeling, and have a reduced risk for LVH when compared to MUHO, in which the eccentric type is more prevalent. Therefore, these results contribute to better understand the pathophysiological mechanisms underlying the cardiac damage in obese subjects, suggesting that different metabolic phenotypes are associated with different myocardial adaptation.

\section{Strengths and Limitations}

A strong point of the present study is represented by having excluded diabetic and hypertensive pharmacological treatment that could interfere with cardiac remodeling. Furthermore, metabolic profile was evaluated through the insulin sensitivity index Matsuda, strongly correlated to euglycemic clamp and LVM was indexed for height ${ }^{2,7}$ that is a more accurate method to avoid underestimating LVH in obese subjects. However, this is a cross-sectional study therefore no causal link can be demonstrated. Another possible limitation of the study may be the absence of information on the presence of sleep apnea, which can further amplify the effect of obesity on cardiac remodeling. Finally, prospective studies on larger populations are needed to evaluate how ventricular remodeling evolves over time in $\mathrm{MHO}$ subjects and its impact on CV risk.

Author Contributions: Conceptualization, A.S., G.S. and F.P.; methodology, A.S. and A.C.; software, A.S. and A.C.; validation, A.S., A.C. and F.P.; formal analysis, A.S. and A.C.; investigation, A.S., A.C., L.M. and S.M.; data curation, A.S., A.C., L.M., S.M., V.C., M.P., T.V.F., F.A. and E.S.; writing-original draft preparation, A.S. and A.C.; writing-review and editing, A.S., A.C., G.S. and F.P.; visualization, L.M., S.M., V.C., M.P., T.V.F., F.A. and E.S.; supervision, A.S., A.C., G.S. and F.P.; project administration, A.S., A.C., G.S. and F.P., A.S. and A.C. equally contributed to the work. All authors have read and agreed to the published version of the manuscript.

Funding: This research received no external funding.

Conflicts of Interest: The authors declare no conflict of interest.

\section{References}

1. Arnlöv, J.; Sundström, J.; Ingelsson, E.; Lind, L. Impact of BMI and the metabolic syndrome on the risk of diabetes in middle-aged men. Diabetes Care 2011, 34, 61-65. [CrossRef]

2. Plourde, G.; Karelis, A.D. Current issues in the identification and treatment of metabolically healthy but obese individuals. Nutr. Metab. Cardiovasc. Dis. 2014, 24, 455-459. [CrossRef]

3. Seo, M.H.; Rhee, E.J. Metabolic and cardiovascular implications of a metabolically healthy obesity phenotype. Endocrinol. Metab. 2014, 29, 427-434. [CrossRef] [PubMed]

4. Succurro, E.; Marini, M.A.; Frontoni, S.; Hribal, M.L.; Andreozzi, F.; Lauro, R.; Perticone, F.; Sesti, G. Insulin secretion in metabolically obese, but normal weight, and in metabolically healthy but obese individuals. Obesity 2008, 16, 1881-1886. [CrossRef] [PubMed] 
5. Sesti, G.; Succurro, E.; Arturi, F.; Andreozzi, F.; Laino, I.; Perticone, M.; Sciacqua, A.; Hribal, M.L.; Perticone, F. IGF-1 levels link estimated glomerular filtration rate to insulin resistance in obesity: A study in obese, but metabolically healthy, subjects and obese, insulin-resistant subjects. Nutr. Metab. Cardiovasc. Dis. 2011, 21, 933-940. [CrossRef] [PubMed]

6. Koren, M.J.; Devereux, R.B.; Casale, P.N.; Savage, D.D.; Laragh, J.H. Relation of left ventricular mass and geometry to morbidity and mortality in uncomplicated essential hypertension. Ann. Intern. Med. 1991, 114, 345-352. [CrossRef]

7. Levy, D.; Garrison, R.J.; Savage, D.D.; Kannel, W.B.; Castelli, W.P. Prognostic implications of echocardiographically determined left ventricular mass in the Framingham Heart Study. N. Engl. J. Med. 1990, 322, 1561-1566. [CrossRef]

8. Sesti, G.; Sciacqua, A.; Scozzafava, A.; Vatrano, M.; Angotti, E.; Ruberto, C.; Santillo, E.; Parlato, G.; Perticone, F. Effects of growth hormone and insulin-like growth factor-1 on cardiac hypertrophy of hypertensive patients. J. Hypertens. 2007, 25, 471-477. [CrossRef]

9. Sciacqua, A.; Miceli, S.; Carullo, G.; Greco, L.; Succurro, E.; Arturi, F.; Sesti, G.; Perticone, F. One-hour postload plasma glucose levels and left ventricular mass in hypertensive patients. Diabetes Care 2011, 34, 1406-1411. [CrossRef]

10. Sesti, G.; Fiorentino, T.V.; Perticone, M.; Sciacqua, A.; Andreozzi, F.; Hribal, M.L.; Perticone, F. Characterization of left ventricular mass in individuals at risk for type 2 diabetes identified by $\mathrm{HbA1c}$ levels according to the American Diabetes Association criteria. Int. J. Cardiol. 2015, 179, 211-213. [CrossRef]

11. Miceli, S.; Maio, R.; Perticone, M.; Tripepi, G.; Sciacqua, A.; Mazzaferro, D.; Sesti, G.; Perticone, F. Creatinine and insulin predict cardiac mass in drug-naïve hypertensive patients. Int. J. Cardiol. 2013, 167, 519-524. [CrossRef] [PubMed]

12. Perticone, F.; Sciacqua, A.; Perticone, M.; Miceli, S.; Maio, R.; Tassone, J.E.; Arturi, F.; Sesti, G. Phenotypic characterization of normotolerant hypertensive patients. Int. J. Cardiol. 2013, 165, 322-326. [CrossRef]

13. Perticone, F.; Maio, R.; Di Paola, R.; Sciacqua, A.; Marucci, A.; De Cosmo, S.; Perticone, M.; Sesti, G.; Trischitta, V. Role of PC-1 and ACE genes on insulin resistance and cardiac mass in never-treated hypertensive patients. Suggestive evidence for a digenic additive modulation. Nutr. Metab. Cardiovasc. Dis. 2007, 17, 181-187. [CrossRef] [PubMed]

14. Ceravolo, R.; Maio, R.; Cuda, G.; Scozzafava, A.; Sciacqua, A.; Vatrano, M.; Bellieni, G.; D’Angelo, G.; Schipani, F.A.; Sesti, G.; et al. Relation of fasting insulin related to insertion/deletion polymorphism of angiotensin-converting enzyme-gene and cardiac mass in never-treated patients with systemic hypertension. Am. J. Cardiol. 2003, 92, 1234-1237. [CrossRef]

15. Li, X.; Li, S.; Ulusoy, E.; Chen, W.; Srinivasan, S.R.; Berenson, G.S. Childhood adiposity as a predictor of cardiac mass in adulthood: The Bogalusa Heart Study. Circulation 2004, 110, 3488-3492. [CrossRef]

16. Guerra, F.; Mancinelli, L.; Angelini, L.; Fortunati, M.; Rappelli, A.; Dessì-Fulgheri, P.; Sarzani, R. The association of left ventricular hypertrophy with metabolic syndrome is dependent on body mass index in hypertensive overweight or obese patients. PLOS ONE 2011, 6, e16630. [CrossRef]

17. Murdolo, G.; Angeli, F.; Reboldi, G.; Di Giacomo, L.; Aita, A.; Bartolini, C.; Vedecchia, P. Left ventricular hypertrophy and obesity: Only a matter of fat? High Blood Press. Cardiovasc. Prev. 2015, 22, 29-41. [CrossRef]

18. Dušan, P.; Tamara, I.; Goran, V.; Gordana, M.L.; Amira, P.A. Left ventricular mass and diastolic function in obese children and adolescents. Pediatr. Nephrol. 2015, 30, 645-652. [CrossRef]

19. Succurro, E.; Marini, M.A.; Arturi, F.; Grembiale, A.; Lugarà, M.; Andreozzi, F.; Sciacqua, A.; Lauro, R.; Hribal, M.L.; Perticone, F.; et al. Elevated one-hour post-load plasma glucose levels identifies subjects with normal glucose tolerance but early carotid atherosclerosis. Atherosclerosis 2009, 207, 245-249. [CrossRef]

20. Gutt, M.; Davis, C.L.; Spitzer, S.B.; Llabre, M.M.; Kumar, M.; Czarnecki, E.M.; Schneiderman, N.; Skyler, J.S.; Marks, J.B. Validation of the insulin sensitivity index (ISI $(0,120))$ : Comparison with other measures. Diabetes Res. Clin. Pract. 2000, 47, 177-184. [CrossRef]

21. Williams, B.; Mancia, G.; Spiering, W.; Agabiti Rosei, E.; Azizi, M.; Burnier, M.; Clement, D.L.; Coca, A.; de Simone, G.; Dominiczak, A.; et al. ESC Scientific Document Group. 2018 ESC/ESH Guidelines for the management of arterial hypertension. Eur. Heart J. 2018, 39, 3021-3104. [CrossRef] [PubMed]

22. Levey, A.S.; Stevens, L.A.; Schmid, C.H.; Zhang, Y.L.; Castro, A.F.; Feldman, H.I.; Kusek, J.W.; Eggers, P.; Van Lente, F.; Greene, T.; et al. CKD-EPI (Chronic Kidney Disease Epidemiology Collaboration). A new equation to estimate glomerular filtration rate. Ann. Intern. Med. 2009, 150, 604-612. [CrossRef] [PubMed] 
23. Marwick, T.H.; Lang, R.M.; Badano, L.P.; Mor-Avi, V.; Afilalo, J.; Armstrong, A.; Ernande, L.; Flachskampf, F.A.; Foster, E.; Goldstein, S.A.; et al. Recommendations for cardiac chamber quantification by echocardiography in adults: An update from the American Society of Echocardiography and the European Association of Cardiovascular Imaging. J. Am. Soc. Echocardiogr. 2015, 28, 233-271. [CrossRef] [PubMed]

24. Devereux, R.B.; Alonso, D.R.; Lutas, E.M.; Gottlieb, G.J.; Campo, E.; Sachs, I.; Reichek, N. Echocardiographic assessment of left ventricular hypertrophy: Comparison to necropsy findings. Am. J. Cardiol. 1986, 57, 450-458. [CrossRef]

25. de Simone, G.; Kizer, J.R.; Chinali, M.; Roman, M.J.; Bella, J.N.; Best, L.G.; Lee, E.T.; Devereux, R.B. Strong Heart Study Investigators. Normalization for body size and population-attributable risk of left ventricular hypertrophy: The Strong Heart Study. Am. J. Hypertens. 2005, 18, 191-196. [CrossRef]

26. Hwang, Y.C.; Jee, J.H.; Kang, M.; Rhee, E.J.; Sung, J.; Lee, M.K. Metabolic syndrome and insulin resistance are associated with abnormal left ventricular diastolic function and structure independent of blood pressure and fasting plasma glucose level. Int. J. Cardiol. 2012, 159, 107-111. [CrossRef]

27. Eckel, R.H.; Grundy, S.M.; Zimmet, P.Z. The metabolic syndrome. Lancet 2005, 365, 1415-1428. [CrossRef]

28. Saltiel, A.R.; Kahn, C.R. Insulin signaling and the regulation of glucose and lipid metabolism. Nature 2001, 414, 799-806. [CrossRef]

29. Dyck, D.J.; Heigenhauser, G.J.F.; Bruce, C.R. The role of adipokines as regulators of skeletal muscle fatty acid metabolism and insulin sensitivity. Acta Physiol. 2006, 186, 5-16. [CrossRef]

30. Lorenzo, M.; Fernández-Veledo, S.; Vila-Bedmar, R.; Garcia-Guerra, L.; De Alvaro, C.; Nieto-Vazquez, I. Insulin resistance induced by tumor necrosis factor-alpha in myocytes and brown adipocytes. J. Anim. sci. 2008, 86 (Suppl. 14), E94-E104. [CrossRef]

31. Perticone, F.; Maio, R.; Sciacqua, A.; Andreozzi, F.; Iemma, G.; Perticone, M.; Zoccali, C.; Sesti, G. Endothelial dysfunction and C-reactive protein are risk factors for diabetes in essential hypertension. Diabetes 2008, 57, 167-171. [CrossRef] [PubMed]

32. Muniyappa, R.; Montagnani, M.; Koh, K.K.; Quon, M.J. Cardiovascular actions of insulin. Endocr. Rev. 2007, 28, 463-491. [CrossRef]

33. Perticone, F.; Sciacqua, A.; Scozzafava, A.; Ventura, G.; Laratta, E.; Pujia, A.; Federici, M.; Lauro, R.; Sesti, G. Impaired endothelial function in never-treated hypertensive subjects carrying the Arg972 polymorphism in the insulin receptor substrate-1 gene. J. Clin. Endocrinol. Metab. 2004, 89, 3606-3609. [CrossRef]

34. Perticone, F.; Sciacqua, A.; Maio, R.; Perticone, M.; Galiano Leone, G.; Bruni, R.; Di Cello, S.; Pascale, A.; Talarico, G.; Greco, L.; et al. Endothelial dysfunction, ADMA and insulin resistance in essential hypertension. Int. J. Cardiol. 2010, 142, 236-241. [CrossRef] [PubMed]

35. Perticone, M.; Cimellaro, A.; Maio, R.; Caroleo, B.; Sciacqua, A.; Sesti, G.; Perticone, F. Additive Effect of Non-Alcoholic Fatty Liver Disease on Metabolic Syndrome-Related Endothelial Dysfunction in Hypertensive Patients. Int. J. Mol. Sci. 2016, 17, 456. [CrossRef] [PubMed]

36. Sciacqua, A.; Perticone, M.; Cimellaro, A.; Tassone, E.J.; Tripepi, G.; Andreucci, M.; Sesti, G.; Perticone, F. Multiplicative effect of serum phosphorus levels and insulin resistance on hypertensive vascular stiffness. Thromb. Haemost. 2016, 115, 227-229. [PubMed]

37. Sciacqua, A.; Marini, M.A.; Hribal, M.L.; Perticone, F.; Sesti, G. Association of insulin resistance indexes to carotid intima-media thickness. PLoS ONE 2013, 8, e53968. [CrossRef]

38. Rutter, M.K.; Parise, H.; Benjamin, E.J.; Levy, D.; Larson, M.G.; Meigs, J.B.; Nesto, R.W.; Wilson, P.W.; Vasan, R.S. Impact of glucose intolerance and insulin resistance on cardiac structure and function: Sex-related differences in the Framingham Heart Study. Circulation 2003, 107, 448-454. [CrossRef]

39. Laustsen, P.G.; Russell, S.J.; Cui, L.; Entingh-Pearsall, A.; Holzenberger, M.; Liao, R.; Kahn, C.R. Essential role of insulin and insulin-like growth factor 1 receptor signaling in cardiac development and function. Mol. Cell Biol. 2007, 27, 1649-1664. [CrossRef]

40. Verdecchia, P.; Reboldi, G.; Schillaci, G.; Borgioni, C.; Ciucci, A.; Telera, M.P.; Santeusanio, F.; Porcellati, C.; Brunetti, P. Circulating insulin and insulin growth factor-1 are independent determinants of left ventricular mass and geometry in essential hypertension. Circulation 1999, 100, 1802-1807. [CrossRef]

41. Perticone, F.; Maio, R.; Sciacqua, A.; Perticone, M.; Laino, I.; Miceli, S.; Mazzaferro, D.; Pascale, A.; Andreozzi, F.; Sesti, G. Insulin-like growth factor-1 and glomerular filtration rate in hypertensive patients. J. Hypertens. 2009, 27, 613-617. [CrossRef] [PubMed] 
42. Vijayan, A.; Franklin, S.C.; Behrend, T.; Hammerman, M.R.; Miller, S.B. Insulin-like growth factor 1 improves renal function in patients with end-stage chronic renal failure. Am. J. Physiol. 1999, 276, R929-R934. [CrossRef] [PubMed]

43. Oliveira-Junior, S.A.; Martinez, P.F.; Guizoni, D.M.; Campos, D.H.; Fernandes, T.; Oliveira, E.M.; Okoshi, M.P.; Okoshi, K.; Padovani, C.R.; Cicogna, A.C. AT1 receptor blockade attenuates insulin resistance and myocardial remodeling in rats with diet-induced obesity. PLOS ONE 2014, 9, e86447. [CrossRef] [PubMed]

44. Niemann, B.; Chen, Y.; Teschner, M.; Li, L.; Silber, R.E.; Rohrbach, S. Obesity induces signs of premature cardiac aging in younger patients: The role of mitochondria. J. Am. Coll. Cardiol. 2011, 57, 577-585. [CrossRef] [PubMed]

45. Müller, M.J.; Lagerpusch, M.; Enderle, J.; Schautz, B.; Heller, M.; Bosy-Westphal, A. Beyond the body mass index: Tracking body composition in the pathogenesis of obesity and the metabolic syndrome. Obes. Rev. 2012, 13, 6-13. [CrossRef]

46. Gottdiener, J.S.; Reda, D.J.; Materson, B.J.; Massie, B.M.; Notargiacomo, A.; Hamburger, R.J.; Williams, D.W.; Henderson, W.G. Importance of obesity, race and age to the cardiac structural and functional effects of hypertension. The Department of Veterans Affairs Cooperative Study Group on Antihypertensive Agents. J. Am. Coll. Cardiol. 1994, 24, 1492-1498. [CrossRef]

47. Sciacqua, A.; Scozzafava, A.; Pujia, A.; Maio, R.; Borrello, F.; Andreozzi, F.; Vatrano, M.; Cassano, S.; Perticone, M.; Sesti, G.; et al. Interaction between vascular dysfunction and cardiac mass increases the risk of cardiovascular outcomes in essential hypertension. Eur. Heart J. 2005, 26, 921-927. [CrossRef]

48. Kardassis, D.; Bech-Hanssen, O.; Schönander, M.; Sjöström, L.; Karason, K. The influence of body composition, fat distribution, and sustained weight loss on left ventricular mass and geometry in obesity. Obesity 2012, 20, 605-611. [CrossRef]

(C) 2020 by the authors. Licensee MDPI, Basel, Switzerland. This article is an open access article distributed under the terms and conditions of the Creative Commons Attribution (CC BY) license (http://creativecommons.org/licenses/by/4.0/). 